\title{
An Etiologic Profile of Anemia in 405 Geriatric Patients
}

\author{
Tabea Geisel, ${ }^{1,2}$ Julia Martin, ${ }^{1,2}$ Bettina Schulze, ${ }^{3}$ Roland Schaefer, ${ }^{4}$ \\ Matthias Bach, ${ }^{3}$ Garth Virgin, ${ }^{5}$ and Jürgen Stein ${ }^{1,2,6}$ \\ ${ }^{1}$ Crohn Colitis Center Rhein-Main, 60594 Frankfurt/Main, Germany \\ ${ }^{2}$ Institute of Nutritional Science, University of Giessen, 35392 Giessen, Germany \\ ${ }^{3}$ St. Elisabethen Krankenhaus, 60487 Frankfurt/Main, Germany \\ ${ }^{4}$ Krankenhaus Sachsenhausen, Teaching Hospital of the J. W. von Goethe University Frankfurt/Main, \\ 60594 Frankfurt/Main, Germany \\ ${ }^{5}$ Vifor Pharma Deutschland GmbH, 81379 Munich, Germany \\ ${ }^{6}$ Department of Gastroenterology and Nutritional Medicine, Krankenhaus Sachsenhausen, \\ Teaching Hospital of the J. W. von Goethe University Frankfurt/Main, 60594 Frankfurt/Main, Germany
}

Correspondence should be addressed to Jürgen Stein; j.stein@em.uni-frankfurt.de

Received 22 November 2013; Accepted 14 January 2014; Published 23 February 2014

Academic Editor: Donald S. Silverberg

Copyright (c) 2014 Tabea Geisel et al. This is an open access article distributed under the Creative Commons Attribution License, which permits unrestricted use, distribution, and reproduction in any medium, provided the original work is properly cited.

Background. Anemia is a common condition in the elderly and a significant risk factor for increased morbidity and mortality, reducing not only functional capacity and mobility but also quality of life. Currently, few data are available regarding anemia in hospitalized geriatric patients. Our retrospective study investigated epidemiology and causes of anemia in 405 hospitalized geriatric patients. Methods. Data analysis was performed using laboratory parameters determined during routine hospital admission procedures (hemoglobin, ferritin, transferrin saturation, C-reactive protein, vitamin B12, folic acid, and creatinine) in addition to medical history and demographics. Results. Anemia affected approximately two-thirds of subjects. Of 386 patients with recorded hemoglobin values, $66.3 \%$ were anemic according to WHO criteria, mostly (85.1\%) in a mild form. Anemia was primarily due to iron deficiency (65\%), frequently due to underlying chronic infection $(62.1 \%)$, or of mixed etiology involving a combination of chronic disease and iron deficiency, with absolute iron deficiency playing a comparatively minor role. Conclusion. Greater awareness of anemia in the elderly is warranted due to its high prevalence and negative effect on outcomes, hospitalization duration, and mortality. Geriatric patients should be routinely screened for anemia and etiological causes of anemia individually assessed to allow timely initiation of appropriate therapy.

\section{Introduction}

Iron deficiency is the most prevalent nutritional deficiency worldwide. This metal ion is an essential element in a variety of physiological processes in human beings, including the production of energy in the brain. Iron is also an enzymatic cofactor in the synthesis of neurotransmitters and myelin and is well known for being especially important as a means of oxygen transportation [1]. The main consequence of iron deficiency is anemia, a common condition and significant problem in the older population. However, many physicians continue to neglect the significance of anemia as a serious clinical condition in the elderly [2]. While decreased hemoglobin levels were previously largely considered a normal consequence of aging, there is now evidence that anemia is associated with an increased risk for morbidity and mortality $[3,4]$. According to hemoglobin $(\mathrm{Hb})$ cut-off levels defined by the World Health Organization (WHO) $(<12 \mathrm{~g} / \mathrm{dL}$ for females, $<13 \mathrm{~g} / \mathrm{dL}$ for males) [5], anemia is present in $10 \%$ of women and $11 \%$ of men over the age of 65 , increasing to $20 \%$ of women and $26 \%$ of men over 85 [6]. An even higher prevalence is seen in hospitalized patients, of whom approximately $40-50 \%$ have been found to be anemic [7]. The primary consequences of anemia, even mild anemia in which hemoglobin values are only marginally reduced $(>9.5 \mathrm{~g} / \mathrm{dL})$, are the impairment of functional capacities and a reduced 
quality of life [8-10]. Furthermore, in elderly persons, anemia can impair physical performance and mobility, thus increasing the risk of falls. An association between anemia in older adults and mortality has been observed in several studies, even in the absence of concomitant illness. In elderly patients, anemia is often overlooked, despite the fact that it has been shown to have potentially serious consequences $[2-5,10]$.

Data describing the prevalence and causes of anemia in hospitalized geriatric populations are rare and incongruent. Our aim was therefore to determine the epidemiology and etiology of anemia in a hospitalized geriatric population in Germany.

\section{Methods}

2.1. Study Design. In this German study, all patients who were admitted between March 2010 and March 2011 to the Geriatric Clinic of the St. Elisabethen Krankenhaus in Frankfurt, Germany, and whose medical records were available were included. The data was analyzed retrospectively.

Patients included in the study were aged 65 years or over. The presence of anemia was defined according to criteria issued by the WHO: hemoglobin $(\mathrm{Hb})<12 \mathrm{~g} / \mathrm{dL}$ for females and $<13 \mathrm{~g} / \mathrm{dL}$ for males. Hb values on admission were available for 386 of the 405 patients (95.3\%) and three grades of anemia severity were differentiated: severe $(\mathrm{Hb}<8 \mathrm{~g} / \mathrm{dL})$, moderate ( $\mathrm{Hb} 8$ to $<9.5 \mathrm{~g} / \mathrm{dL}$ ), and mild $(\mathrm{Hb} \geq 9.5 \mathrm{~g} / \mathrm{dL})$. In addition, patient data were assessed for routinely determined levels of serum iron (in $92.6 \%$ of patients), serum ferritin (95.6\%), transferrin saturation (TSAT) $(99.0 \%)$, vitamin $\mathrm{B}_{12}$ (91.9\%), folic acid (88.1\%), CRP (96.8\%), and serum creatinine (99.51\%).

\subsubsection{Definition of Anemia Classification}

Anemia Associated with Iron Deficiency. Patients with $\mathrm{Hb}$ levels under $12 \mathrm{~g} / \mathrm{dL}$ (women) and $13 \mathrm{~g} / \mathrm{dL}$ (men) and a TSAT value $<20 \%$ were considered to have anemia associated with iron deficiency. Three subcategories were defined.

(i) Anemia related to absolute iron deficiency (iron deficiency anemia, IDA) was characterized by a decreased serum ferritin level $(<30 \mu \mathrm{g} / \mathrm{mL})$ in combination with low serum CRP levels $(\leq 0.5 \mathrm{mg} / \mathrm{dL})$.

(ii) Anemia caused by inflammation (AI) was defined by high ferritin levels $(>100 \mu \mathrm{g} / \mathrm{mL})$ and increased CRP $(\geq 0.5 \mathrm{mg} / \mathrm{dL}$ ).

(iii) Patients with ferritin levels between $30 \mu \mathrm{g} / \mathrm{mL}$ and $100 \mu \mathrm{g} / \mathrm{mL}$ and high CRP levels $(\geq 0.5 \mathrm{mg} / \mathrm{dL})$ were classified as having mixed anemia (IDA/AI).

Anemia due to Factors Other Than Iron Deficiency. Patients with $\mathrm{Hb}$ levels under $12 \mathrm{~g} / \mathrm{dL}$ (women) and $13 \mathrm{~g} / \mathrm{dL}$ (men) and a TSAT value $\geq 20 \%$ were considered to have anemia caused by factors other than iron deficiency. Four subcategories were defined.

(i) Anemia secondary to cobalamin deficiency was diagnosed if the serum level was $<150 \mathrm{pg} / \mathrm{mL}$.

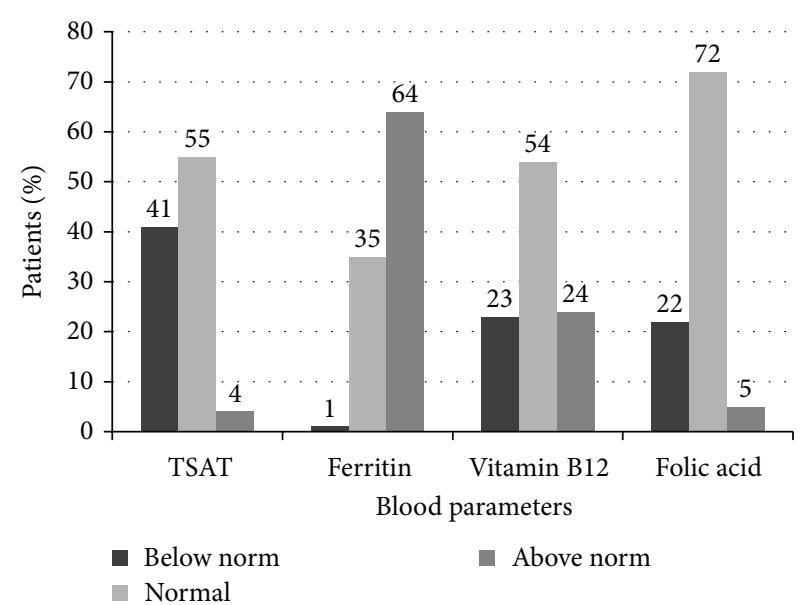

FIgURE 1: Anemia-related laboratory parameters at time of admission (TSAT $=$ transferrin saturation).

(ii) Anemia secondary to folic acid deficiency was diagnosed if the serum level was $<2 \mu \mathrm{g} / \mathrm{L}$.

(iii) Anemia of chronic renal insufficiency (CRI) was classified by creatinine values $>1.2 \mathrm{mg} / \mathrm{dL}$ in females and $>1.5 \mathrm{mg} / \mathrm{dL}$ in males [11-13].

(iv) Anemia secondary to other etiologies was defined as unexplained anemia (UA) [6]. See Figure 1.

2.2. Statistical Analysis. The primary objective of this study was to determine the prevalence of anemia and of different etiological subtypes of anemia in a hospitalized geriatric patient population.

Descriptive statistics were attained through the calculation of arithmetical means, standard deviations, and minimum and maximum values of all data. To test the significance of all categorical variables, the Chi-squared test (Pearson) was performed. Arithmetical means were calculated with $t$-tests for dependent and independent samples, and correlations were determined using the Spearman Rho method. All outcomes with a minimum of $P<0.05$ were considered significant. Missing values were disregarded in all statistical tests. All statistical analyses were performed using IBM SPSS Statistics 20SPSS statistical software.

\section{Results}

During the period studied, 405 patients (116 men and 289 women) who were admitted to the geriatric clinic had medical records available and were therefore included in the study. The average age was $83.6 \pm 6.9$ years (range 65-101 years). The patients were divided into three observational groups according to age: 65 to 75 years, 76 to 85 years, and over 85 years of age, representing $12.10 \%, 36.79 \%$, and $51.11 \%$ of the study population, respectively.

The most frequent main causes of hospitalization in this geriatric patient group were fractures $(39.4 \%, n=150)$, cardiovascular disease $(18.4 \%, n=70)$, and disturbances of gait and mobility $(16.8 \%, n=64)$. Other reasons for 
TABLE 1: Anemia subtypes according to main reason for hospitalization.

\begin{tabular}{|c|c|c|c|c|c|c|c|c|}
\hline & $\begin{array}{c}\text { All patients } \\
n=368 \\
n\left(\%^{*}\right)\end{array}$ & $\begin{array}{c}\text { All anemic } \\
\text { patients } \\
n=241 \\
n\left(\%^{* 1}\right)\end{array}$ & $\begin{array}{c}\text { IDA } \\
n\left(\%^{* 1}\right)\end{array}$ & $\begin{array}{l}\text { IDA/AI } \\
n(\% * 1)\end{array}$ & $\begin{array}{c}\mathrm{AI} \\
n\left(\%^{* 1}\right)\end{array}$ & $\begin{array}{c}\mathrm{B}_{12} / \text { folic acid } \\
\text { deficiency } \\
n\left(\%^{* 1}\right)\end{array}$ & $\begin{array}{c}\text { Renal anemia } \\
n\left(\%{ }^{* 1}\right)\end{array}$ & $\begin{array}{c}\mathrm{UA} \\
n\left(\%^{* 1}\right)\end{array}$ \\
\hline Fractures & $150(40.76)$ & $110(43.90)$ & $0(0)$ & $9(8.18)$ & $31(28.18)$ & $8(7.27)$ & $10(9.09)$ & $52(47.27)$ \\
\hline $\begin{array}{l}\text { Cardiovascular } \\
\text { disease }\end{array}$ & $70(19.02)$ & $40(57.14)$ & $3(7.50)$ & $6(15.00)$ & $15(37.50)$ & $3(7.50)$ & $7(17.50)$ & $6(15.00)$ \\
\hline $\begin{array}{l}\text { Disturbance of gait } \\
\text { and mobility }\end{array}$ & $64(17.39)$ & $26(40.63)$ & $1(3.85)$ & $5(19.23)$ & $3(11.54)$ & $2(7.69)$ & $5(19.23)$ & $10(38.46)$ \\
\hline $\begin{array}{l}\text { Digestive tract } \\
\text { diseases }\end{array}$ & $15(4.08)$ & $13(86.67)$ & $1(7.69)$ & $2(15.38)$ & $4(30.77)$ & $2(15.38)$ & $4(30.77)$ & $0(0)$ \\
\hline $\begin{array}{l}\text { Disorders of the } \\
\text { musculoskeletal } \\
\text { apparatus }\end{array}$ & $14(3.80)$ & $13(92.86)$ & $0(0)$ & $1(7.69)$ & $3(23.08)$ & $3(23.08)$ & $6(46.15)$ & $0(0)$ \\
\hline Neoplasma & $14(3.80)$ & $10(71.43)$ & $0(0)$ & $1(10)$ & $6(60.00)$ & $2(20)$ & $1(10)$ & $0(0)$ \\
\hline Infectious diseases & $9(2.45)$ & $7(77.78)$ & $1(14.29)$ & $2(28.57)$ & $2(28.57)$ & $1(14.29)$ & $1(14.92)$ & $0(0)$ \\
\hline Injuries & $9(2.45)$ & $4(44.44)$ & $0(0)$ & $2(50.00)$ & $0(0)$ & $1(25.00)$ & $1(25)$ & $0(0)$ \\
\hline \multirow{2}{*}{ Other reasons } & $23(6.25)$ & $18(78.26)$ & $1(5.56)$ & $3(16.67)$ & $4(22.22)$ & 2 (11.11) & $4(22.22)$ & $4(22.22)$ \\
\hline & & $241(100)$ & $7\left(2.90^{* 2}\right)$ & $31\left(12.86^{* 2}\right)$ & $68\left(28.22^{* 2}\right)$ & $24\left(9.96^{* 2}\right)$ & $39\left(16.18^{* 2}\right)$ & $72\left(29.88^{* 2}\right)$ \\
\hline
\end{tabular}

${ }^{*}$ Relating to all hospitalized patients.

${ }^{* 1}$ Relating to all anemic patients with this diagnosis.

${ }^{* 2}$ Relating to all anemic patients.

TABLE 2: Iron parameters in all patients subdivided into age groups.

\begin{tabular}{|c|c|c|c|c|c|c|c|c|c|c|}
\hline \multirow{3}{*}{$\mathrm{Hb}(\mathrm{g} / \mathrm{dL})$} & \multicolumn{2}{|c|}{ Number of patients } & \multicolumn{2}{|c|}{ Mean \pm SD } & \multicolumn{2}{|c|}{ Median } & \multicolumn{2}{|c|}{ Min. } & \multicolumn{2}{|c|}{ Max. } \\
\hline & Female & Male & Female & Male & Female & Male & Female & Male & Female & Male \\
\hline & & & & & & & & & & \\
\hline 65-75 years & 33 & 21 & $11.67 \pm 3.01$ & $11.84 \pm 2.05$ & 11.5 & 11.6 & 9 & 8.5 & 19.5 & 16.5 \\
\hline $76-85$ years & 97 & 59 & $11.58 \pm 2.24$ & $11.91 \pm 1.81$ & 11.6 & 11.4 & 8.1 & 9.1 & 19.7 & 16.2 \\
\hline$>85$ years & 149 & 29 & $11.30 \pm 2.0$ & $11.94 \pm 1.97$ & 11.4 & 12.4 & 8.1 & 8.9 & 16.9 & 16.2 \\
\hline Serum iron $(\mathrm{mg}$ & & & & & & & & & & \\
\hline $65-75$ years & 32 & 19 & $3.53 \pm 1.93$ & $5.05 \pm 3.08$ & 3 & 5 & 1 & 1 & 8 & 9 \\
\hline $76-85$ years & 97 & 57 & $4.15 \pm 2.36$ & $4.26 \pm 2.117$ & 4 & 5 & 1 & 1 & 9 & 8 \\
\hline$>85$ years & 142 & 27 & $4.7 \pm 2.38$ & $3.85 \pm 2.37$ & 5 & 4 & 1 & 1 & 9 & 8 \\
\hline Serum ferritin & & & & & & & & & & \\
\hline $65-75$ years & 35 & 22 & $184.14 \pm 206.62$ & $371.36 \pm 232.83$ & 116 & 314 & 29 & 41 & 1131 & 905 \\
\hline $76-85$ years & 94 & 58 & $262.38 \pm 263.06$ & $336.71 \pm 284.13$ & 201.5 & 253 & 18 & 56 & 2026 & 1435 \\
\hline$>85$ years & 149 & 27 & $262.38 \pm 263.06$ & $336.56 \pm 291.14$ & 212 & 216 & 7 & 38 & 1352 & 1250 \\
\hline TSAT (\%) & & & & & & & & & & \\
\hline $65-75$ years & 36 & 22 & $18.64 \pm 12.35$ & $18.18 \pm 9.39$ & 15 & 18.5 & 4 & 4 & 60 & 35 \\
\hline $76-85$ years & 100 & 61 & $20.44 \pm 12.39$ & $21.44 \pm 11.61$ & 18 & 20 & 3 & 6 & 87 & 67 \\
\hline$>85$ years & 153 & 30 & $19.62 \pm 10.03$ & $20.97 \pm 14.41$ & 17 & 18 & 5 & 6 & 52 & 79 \\
\hline CRP (mg/dL) & & & & & & & & & & \\
\hline 65-75 years & 35 & 22 & $4.77 \pm 6.29$ & $1.47 \pm 1.85$ & 2.3 & 0.65 & 0.2 & 0.2 & 28.7 & 7.4 \\
\hline $76-85$ years & 127 & 82 & $4.77 \pm 6.29$ & $2.19 \pm 4.02$ & 1.7 & 0.95 & 0 & 0.2 & 28.7 & 30 \\
\hline$>85$ years & 151 & 28 & $3.88 \pm 6.08$ & $1.7 \pm 0.7$ & 1.9 & 0.7 & 0 & 0 & 49 & 9.8 \\
\hline
\end{tabular}

admission were digestive tract diseases $(3.9 \%, n=15)$, disorders of the musculoskeletal apparatus $(3.7 \%, n=14)$, neoplasms $(3.7 \%, n=14)$, infectious diseases $(2.4 \%, n=9)$, and injuries $(2.4 \%, n=9)$, with a further $6.0 \%(n=23)$ admitted for other reasons.

Table 1 shows the distribution of these conditions according to specific anemia subtypes. On average, the patients had eight additional diagnoses concurrent to the primary diagnosis, and mean duration of stay in the clinic of all study subjects was 22 days. The main demographic characteristics of the patients are summarized in Table 2.

Of those hospitalized patients whose $\mathrm{Hb}$ values at admission were available $(n=386), 66.3 \%$ ( $74.8 \%$ of men and $62.9 \%$ of women) were anemic. There was no correlation between 
age and $\mathrm{Hb}$ level. While only four patients (1.5\%) were found to be severely anemic, 37 (13.5\%) had moderate anemia and the remaining $85.1 \%$ were categorized as having mild anemia.

The total number of patients diagnosed with anemia was 237, of whom $154(65.0 \%)$ were defined as having iron deficiency anemia, with TSAT values $<20 \%$. Absolute IDA was found in only 7 (4.6\%) of these patients, while 33 (21.4\%) had a combination of IDA and AI. The majority of patients with IDA ( $n=95,61.7 \%)$ were diagnosed with AI, indicated by high CRP and ferritin levels.

Decreased levels of vitamin $B_{12}$ or folic acid were determined as the cause of anemia in 30 patients (5.9\% and 6.8\%, resp.). In a further $46(19.4 \%)$ study subjects, anemia was found to be the result of chronic renal insufficiency. The remaining patients fell into none of these categories and were therefore classified as having "unexplained anemia."

The mean serum ferritin level of $315.7 \mu \mathrm{g} / \mathrm{L}$ fell within the normal reference range. Serum ferritin values were, however, increased in the majority of study subjects (64\%), while 35\% were found to have normal serum ferritin levels.

\section{Discussion}

Anemia is a common condition in the elderly, especially in hospitalized geriatric patients, and is known to be associated with increased morbidity and mortality. The present study was specifically aimed at investigating the epidemiology and etiology of anemia in a hospitalized geriatric population. Blood samples were retrospectively analyzed for the purpose of the study.

The most striking conclusion drawn is the high prevalence of anemia across the board in elderly patients admitted to hospital owing to a wide range of different disorders. Two-thirds of the patients studied were found to be anemic on admission. Although one other study, also focusing on geriatric inpatients, has shown a similar prevalence of anemia [7], most research involving elderly subjects has found the prevalence to be lower $[6,10,14]$. This discrepancy may be accountable to the fact that, in contrast to the current study with its population of hospitalized elderly patients, most other studies have examined ambulant patients or older people in the community $[15,16]$. Geriatric persons with health problems severe enough to result in hospital admission are more likely than the geriatric population as a whole to suffer from acute infection and also to have an increased risk of blood loss due to surgery. Thus, hospitalized patients are at a higher risk of developing anemia [17]. Anemia was found in most cases to be mild, with an $\mathrm{Hb}$ level $>10 \mathrm{~g} / \mathrm{dL}$, in accordance with previously published results $[6,18]$. However, even mild anemia is frequently associated with negative outcomes with regard to mortality and morbidity in the elderly $[2,19]$ and should therefore not be accepted as a normal physiological response to the aging process. Furthermore, the etiological origins of anemia must be determined in all cases in order to facilitate the choice and implementation of effective therapy. It might be seen as a limitation of the present study that reasons for hospital admission were not taken into account. However, we deliberately chose to include all geriatric patients admitted to our clinic, independent of grounds for hospitalization, in order to gain a broader perspective on the prevalence and causes of anemia in elderly patients.

No statistically significant correlation was detected between patients' age and $\mathrm{Hb}$ values. This is not in keeping with results of previous research, which have suggested an age-related decrease in $\mathrm{Hb}$ levels [6]. Again, this may relate to the specific elderly population included, since all study subjects had serious health issues (and thus, presumably, an increased risk of anemia), whereas in the geriatric population as a whole, the prevalence of serious illness increases with age. Thus, in terms of general state of health, the older the hospitalized patients are, the more representative they can be considered to be of the general population in that age group. As a consequence, what might be considered an innate "bias" of our population towards seriously ill patients (in comparison to studies involving nonhospitalized geriatric persons) is not independent of age, but probably more pronounced in the context of the younger geriatric population.

Determination of the underlying cause of anemia in geriatric persons is complicated by comorbidity and polypharmacy, which are particularly common among the elderly [5]. This must also be taken into account when classifying and comparing the results.

Nonetheless, anemia in the elderly can generally be categorized into four major types: anemia related to nutrient deficiencies (iron, cobalamin, and folic acid), anemia related to chronic inflammation, anemia due to renal insufficiency, and unexplained anemia [6].

Of 237 patients considered to be anemic, 154 (65.0\%) had TSAT values $<20 \%$ and were therefore diagnosed with iron deficiency anemia. In terms of the classification of anemia, the most common etiological subtypes were anemia of inflammation or a mixed form resulting from AI and IDA. Only a few studies have investigated the etiologic profile of anemia in hospitalized patients in the age range from 65 to 101 years $[7,14]$. Comparing our results to previous studies is complicated by differences in anemia classification. However, inflammation seems to be the predominant cause of anemia in the observed population, with nutritive factors playing only a limited role [14]. In elderly persons, the causes of anemia vary depending on their clinical setting. AI and IDA are, however, the most common forms of anemia both in community-dwelling and in hospitalized geriatric patients [14]. In our study, IDA was less prevalent than expected in light of results obtained in prior studies.

Only $4.6 \%$ of our study subjects with iron deficiencyassociated anemia were found to have absolute iron deficiency anemia (IDA), in comparison to $17 \%$ in previous reports $[6,20]$. A possible explanation for this discrepancy might be the higher mean age (83.6 years) of our patients compared to populations of similar studies, whose mean ages were between 77 and 80 years [13, 21]. Furthermore, we had a high number of comorbidities in our study population. A recent study with a comparable prevalence of comorbidities disclosed an IDA rate of 31\% [7]. 
Sixty-two percent of patients with iron deficiency-related anemia were diagnosed with AI. Petrosyan et al. reported a similar prevalence rate $(60 \%)$ of AI in a comparable study population [7]. Prevalence rates in community-dwelling elderly persons, however, may be considerably lower. For example, the NHANES (National Health and Nutrition Examination Survey) III demonstrated a prevalence of $24 \%$ for this type of anemia in a community-dwelling elderly population [6]. Considerable differences in prevalence may be accountable to the setting (community-dwelling elderly, nursing home residents, or hospital patients), variations in mean age of the study population, and the resultant respective variations in the number of comorbidities and chronic conditions. While AI predominantly occurs as a consequence of chronic or long-term illness or infection, it is also associated with malignancy and inflammatory disorders. These are conditions whose prevalence increases with advancing age and which are more likely to be encountered in a hospitalized setting. Since fractures were the most frequent main cause of hospitalization in our study population, these patients came into the rehabilitation ward. Since an increase in inflammation parameters (CRP and ferritin) is to be expected under these circumstances, this represents an additional explanation for the high prevalence of AI in our study [22]. Studies of noninstitutionalized older persons have demonstrated higher and lower prevalences of IDA and AI, respectively $[21,23]$.

In our study, anemia of mixed etiology resulting from iron deficiency and chronic inflammation was also analyzed. Thirty-three patients (21.43\%) were found to have combined IDA and AI.

Anemia due to deficiencies of vitamin $\mathrm{B}_{12}$ or folic acid was found in $5.91 \%$ and $6.75 \%$ of patients, respectively. Other studies showed higher prevalence rates of $10-20 \%$ for cobalamin and $21 \%$ for folic acid deficiency [7, 24, 25]. Guralnik et al. determined anemia secondary to folic acid or cobalamin deficiency in $14 \%$ of their elderly population [6]. However, comparison of these results is of limited value, as different diagnostic criteria were used.

Anemia of chronic renal insufficiency (CRI) was defined by creatinine values $>1.2 \mathrm{mg} / \mathrm{dL}$ in females and $>1.5 \mathrm{mg} / \mathrm{dL}$ in males. Forty-seven (19.41\%) of the elderly patients assessed were found to have CRI-related anemia. While previous studies have reported a prevalence of $8-17.5 \%$ for anemia resulting from renal insufficiency, most of these studies used a glomerular filtration rate (GFR) of $<30 \mathrm{~mL} / \mathrm{min}$ as the defining criterion for chronic kidney disease [7, 26, 27]. While GFR is indeed considered a better parameter for the diagnosis of chronic renal insufficiency, the present study, due to its retrospective design, was only able to assess chronic renal illness on the basis of the available creatinine values. The results of the studies are therefore not directly comparable.

The patients that fell into none of the given etiological subgroup categories were therefore classified as having unexplained anemia. Possible underlying mechanisms for unexplained anemia include physiological changes such as higher circulating levels of proinflammatory cytokines, myelodysplasia, decreased androgen levels, and a decrease in the proliferative capacity of bone marrow stem cells $[6,28]$.
Our study has strengths and limitations. The most limiting factor is the retrospective design of the study. Consequently, only those laboratory parameters which were collected as clinical routine on admission were available to be assessed.

Important strengths of the study are the large study population ( $n=405)$, the wide spectrum of reasons for admission and of underlying disease or condition, and the use of a variety of different iron and inflammation parameters as assessment criteria for the classification of different causes of anemia.

Conclusive evidence from a large number of studies has confirmed that adequate treatment of iron deficiency significantly improves rates of mortality and morbidity in patients suffering from a wide range of conditions, including chronic heart failure [29, 30], coronary heart disease [31], chronic kidney disease [32, 33], cancer [34, 35], and rheumatoid arthritis $[36,37]$. Nevertheless, screening and treatment of ID continue to be widely neglected in the routine management of geriatric patients. There is clearly a need for greater awareness of the high prevalence of anemia in the elderly and of its significance in terms of poorer outcomes, prolonged hospital stays, and increased mortality. Our study underlines the importance of routine screening and individual assessment of the etiological causes of anemia in geriatric patients, allowing the timely initiation of optimal and appropriate therapy. In addition, the perioperative administration of intravenous iron is advisable in order to reduce anemia-related complications and minimize transfusion requirements.

Rather than relying on a single biomarker, screening should include a range of parameters including TSAT, serum ferritin, and CRP. A new generation of intravenous iron preparations allows rapid single-session doses of up to $1,000 \mathrm{mg}$, thus offering an excellent option for effective treatment and prevention of iron deficiency in all patients, including the elderly [38]. Dosage can be calculated using standard calculation methods such as the Ganzoni formula.

\section{Abbreviations}

AI: $\quad$ Anemia of inflammation

CRI: Chronic renal insufficiency

CRP: C-reactive protein

GFR: Glomerular filtration rate

IDA: Iron deficiency anemia

NHANES: National Health and Nutrition

Examination Survey

TSAT: Transferrin saturation

UA: Unexplained anemia

WHO: World Health Organization.

\section{Conflict of Interests}

Tabea Geisel, Julia Martin, and Bettina Schulze have no conflict of interests.

\section{Authors' Contribution}

All authors contributed to the concept and design of the work and to the acquisition and interpretation of data. Tabea 
Geisel drafted the paper. All authors revised the paper for important intellectual content and approved the final version for publication.

\section{Acknowledgments}

The sponsor's role was limited to financial support only. The sponsor took no active part in data collection, data analysis, data interpretation, or paper preparation. The authors would like to thank Janet Collins for proof reading and language support. Garth Virgin is an employee of Vifor Pharma Deutschland GmbH. Roland Schaefer has acted as a consultant for Vifor Pharma Deutschland GmbH. Matthias Bach has received speaker honoraria for Vifor Pharma Deutschland $\mathrm{GmbH}$. Jürgen Stein has received speaker honoraria and is a member of the board of Vifor Pharma Deutschland GmbH.

\section{References}

[1] R. R. Crichton, S. Wilmet, R. Legssyer, and R. J. Ward, "Molecular and cellular mechanisms of iron homeostasis and toxicity in mammalian cells," Journal of Inorganic Biochemistry, vol. 91, no. 1, pp. 9-18, 2002.

[2] A. R. Nissenson, L. T. Goodnough, and R. W. Dubois, "Anemia: not just an innocent bystander?" Archives of Internal Medicine, vol. 163, no. 12, pp. 1400-1404, 2003.

[3] S. D. Denny, M. N. Kuchibhatla, and H. J. Cohen, "Impact of anemia on mortality, cognition, and function in communitydwelling elderly," American Journal of Medicine, vol. 119, no. 4, pp. 327-334, 2006.

[4] B. W. J. H. Penninx, M. Pahor, R. C. Woodman, and J. M. Guralnik, "Anemia in old age is associated with increased mortality and hospitalization," Journals of Gerontology A, vol. 61, no. 5, pp. 474-479, 2006.

[5] World Health Organization, "Nutritional Anemia: Report of a WHO Scientific Group," Technical Report Series, vol. 405, pp. 140, 1968.

[6] J. M. Guralnik, R. S. Eisenstaedt, L. Ferrucci, H. G. Klein, and R. C. Woodman, "Prevalence of anemia in persons 65 years and older in the United States: evidence for a high rate of unexplained anemia," Blood, vol. 104, no. 8, pp. 2263-2268, 2004.

[7] I. Petrosyan, G. Blaison, and E. Andrés, "Anaemia in the elderly: an aetiologic profile of a prospective cohort of 95 hospitalised patients," European Journal of Internal Medicine, vol. 23, pp. 524-528, 2012.

[8] A. A. Lash and S. M. Coyer, "Anemia in older adults," Medsurg Nursing, vol. 17, no. 5, pp. 298-305, 2008.

[9] D. R. Thomas, "Anemia and quality of life: unrecognized and undertreated," Journals of Gerontology A, vol. 59, no. 3, pp. 238241, 2004.

[10] W. P. J. den Elzen, J. M. Willems, R. G. J. Westendorp, A. J. M. De Craen, W. J. J. Assendelft, and J. Gussekloo, "Effect of anemia and comorbidity on functional status and mortality in old age: results from the Leiden 85-plus Study," Canadian Medical Association Journal, vol. 181, no. 3-4, pp. 151-157, 2009.

[11] G. Weiss and L. T. Goodnough, "Anemia of chronic disease," New England Journal of Medicine, vol. 352, no. 10, pp. 1011-1059, 2005.

[12] C. Gasche, A. Berstad, R. Befrits et al., "Guidelines on the diagnosis and management of iron deficiency and anemia in inflammatory bowel diseases," Inflammatory Bowel Diseases, vol. 13, no. 12, pp. 1545-1553, 2007.

[13] E. Joosten, W. Pelemans, M. Hiele, J. Noyen, R. Verhaeghe, and M. A. Boogaerts, "Prevalence and causes of anaemia in a geriatric hospitalized population," Gerontology, vol. 38, no. 1-2, pp. 111-117, 1992.

[14] M. Tettamanti, U. Lucca, F. Gandini et al., "Prevalence, incidence and types of mild anemia in the elderly: the "Health and Anemia" population-based study," Haematologica, vol. 95, no. 11, pp. 1849-1856, 2010.

[15] E. M. Inelmen, M. D’Alessio, M. R. A. Gatto et al., "Descriptive analysis of the prevalence of anemia in a randomly selected sample of elderly people living at home: some results of an Italian multicentric study," Aging, vol. 6, no. 2, pp. 81-89, 1994.

[16] M. E. Salive, J. Cornoni-Huntley, J. M. Guralnik et al., "Anemia and hemoglobin levels in older persons: relationship with age, gender, and health status," Journal of the American Geriatrics Society, vol. 40, no. 5, pp. 489-496, 1992.

[17] E. A. Price, R. Mehra, T. H. Holmes, and S. L. Schrier, "Anemia in older persons: etiology and evaluation," Blood Cells, Molecules, and Diseases, vol. 46, no. 2, pp. 159-165, 2011.

[18] R. Eisenstaedt, B. W. J. H. Penninx, and R. C. Woodman, "Anemia in the elderly: current understanding and emerging concepts," Blood Reviews, vol. 20, no. 4, pp. 213-226, 2006.

[19] L. Ferrucci, J. M. Guralnik, S. Bandinelli et al., "Unexplained anaemia in older persons is characterised by low erythropoietin and low levels of pro-inflammatory markers," British Journal of Haematology, vol. 136, no. 6, pp. 849-855, 2007.

[20] B. J. Anía, V. J. Suman, V. F. Fairbanks, and L. J. Melton III, "Prevalence of anemia in medical practice: community versus referral patients," Mayo Clinic Proceedings, vol. 69, no. 8, pp. 730-735, 1994.

[21] A. A. Merchant and C. N. Roy, "Not so benign haematology: anaemia of the elderly," British Journal of Haematology, vol. 156, no. 2, pp. 173-185, 2012.

[22] P. P. Vinha, A. A. Jordão Jr., J. A. Farina Jr., H. Vannucchi, J. S. Marchini, and S. F. D. C. da Cunha, "Inflammatory and oxidative stress after surgery for the small area corrections of burn sequelae," Acta Cirurgica Brasileira, vol. 26, no. 4, pp. 320$324,2011$.

[23] O. J. Kirkeby, S. Fossum, and C. Risoe, "Anaemia in elderly patients. Incidence and causes of low haemoglobin concentration in a city general practice," Scandinavian Journal of Primary Health Care, vol. 9, no. 3, pp. 167-171, 1991.

[24] L. C. Pennypacker, R. H. Allen, J. P. Kelly et al., "High prevalence of cobalamin deficiency in elderly outpatients," Journal of the American Geriatrics Society, vol. 40, no. 12, pp. 1197-1204, 1992.

[25] R. Carmel, R. Green, D. S. Rosenblatt, and D. Watkins, "Update on cobalamin, folate, and homocysteine," Hematology, vol. 2003, pp. 62-81, 2003.

[26] A. S. Artz and M. J. Thirman, "Unexplained anemia predominates despite an intensive evaluation in a racially diverse cohort of older adults from a referral anemia clinic," Journals of Gerontology A, vol. 66, no. 8, pp. 925-932, 2011.

[27] B. Terrier, M. Resche-Rigon, E. Andres et al., "Prevalence, characteristics and prognostic significance of anemia in daily practice," QJM, vol. 105, no. 4, Article ID hcr230, pp. 345-354, 2012.

[28] L. Ferrucci, R. D. Semba, J. M. Guralnik et al., "Proinflammatory state, hepcidin, and anemia in older persons," Blood, vol. 115, no. 18, pp. 3810-3816, 2010. 
[29] M. Kapoor, M. D. Schleinitz, A. Gemignani, and W. C. Wu, "Outcomes of patients with chronic heart failure and iron deficiency treated with intravenous iron: a meta-analysis," Cardiovascular \& Hematological Disorders-Drug Targets, vol. 13, pp. 35-44, 2013.

[30] E. A. Jankowska, S. von Haehling, S. D. Anker, I. C. Macdougall, and P. Ponikowski, "Iron deficiency and heart failure: diagnostic dilemmas and therapeutic perspectives," European Heart Journal, vol. 34, pp. 816-829, 2013.

[31] N. S. Belousova, S. A. Il'ina, G. É. Chernogoriuk, and L. I. Tiukalova, "The influence of correction of iron metabolism and erythron characteristics in mild iron deficiency states on clinical manifestations of coronary heart disease," Klinicheskaia Meditsina, vol. 90, pp. 41-46, 2012.

[32] G. Wong, K. Howard, E. Hodson, M. Irving, and J. C. Craig, "An economic evaluation of intravenous versus oral iron supplementation in people on haemodialysis," Nephrology Dialysis Transplantation, vol. 28, pp. 413-420, 2013.

[33] D. W. Coyne, T. Kapoian, W. Suki et al., "Ferric gluconate is highly efficacious in anemic hemodialysis patients with high serum ferritin and low transferrin saturation. Results of the Dialysis Patients' Response to IV Iron with Elevated Ferritin (DRIVE) study," Journal of the American Society of Nephrology, vol. 18, no. 3, pp. 975-984, 2007.

[34] A. Gafter-Gvili, B. Rozen-Zvi, and L. Vidal, "Intravenous iron supplementation for the treatment of chemotherapy-induced anaemia-systematic review and meta-analysis of randomised controlled trials," Acta Oncologica, vol. 52, pp. 18-29, 2013.

[35] H. T. Steinmetz, "The role of intravenous iron in the treatment of anemia in cancer patients," Therapeutic Advances in Hematology, vol. 3, pp. 177-191, 2012.

[36] E. Bloxham, V. Vagadia, K. Scott et al., "Anaemia in rheumatoid arthritis: can we afford to ignore it?" Postgraduate Medical Journal, vol. 87, no. 1031, pp. 596-600, 2011.

[37] W.-S. Chen, C.-Y. Liu, H.-T. Lee et al., "Effects of intravenous iron saccharate on improving severe anemia in rheumatoid arthritis patients," Clinical Rheumatology, vol. 31, no. 3, pp. 469477, 2012.

[38] W. Y. Qunibi, "The efficacy and safety of current intravenous iron preparations for the management of iron-deficiency anaemia: a review," Arzneimittel-Forschung, vol. 60, no. 6 a, pp. 399-412, 2010. 


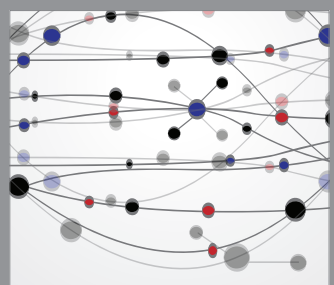

The Scientific World Journal
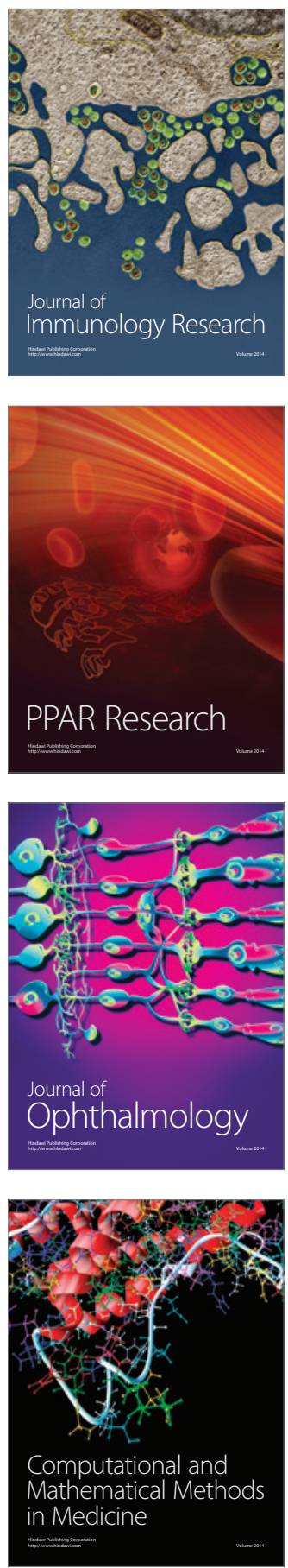

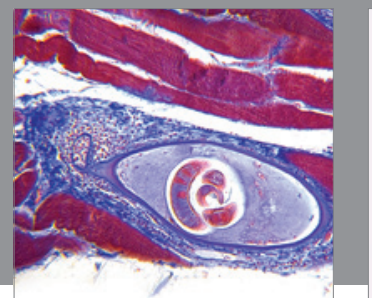

Gastroenterology

Research and Practice
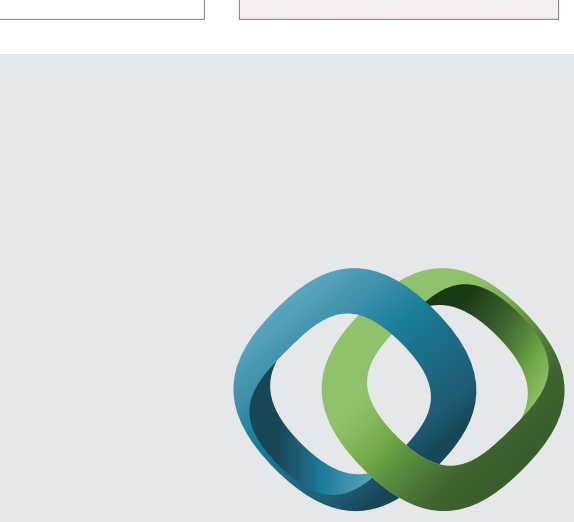

\section{Hindawi}

Submit your manuscripts at

http://www.hindawi.com
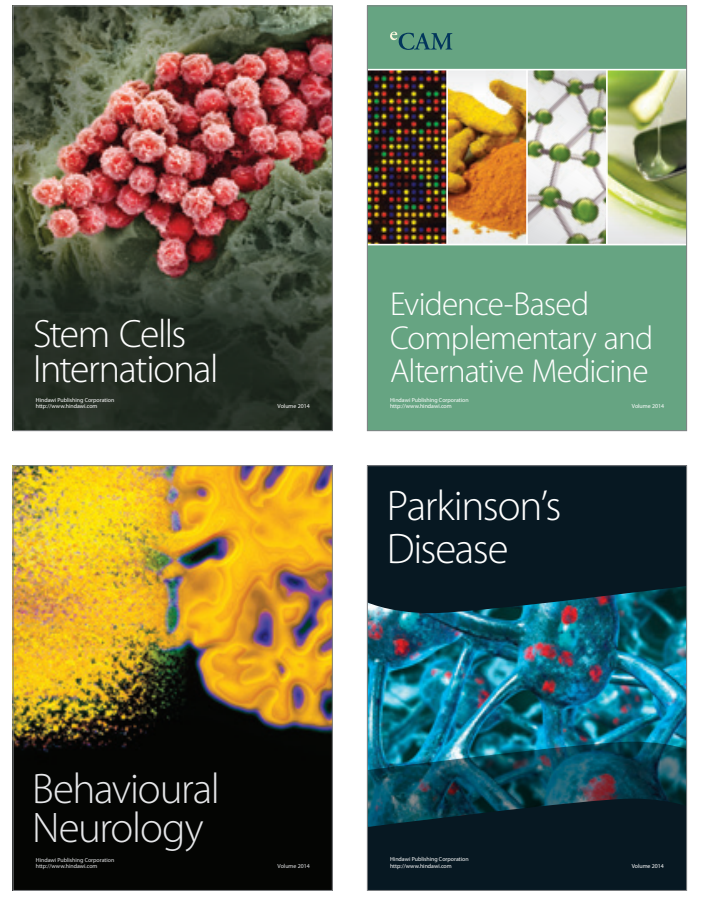
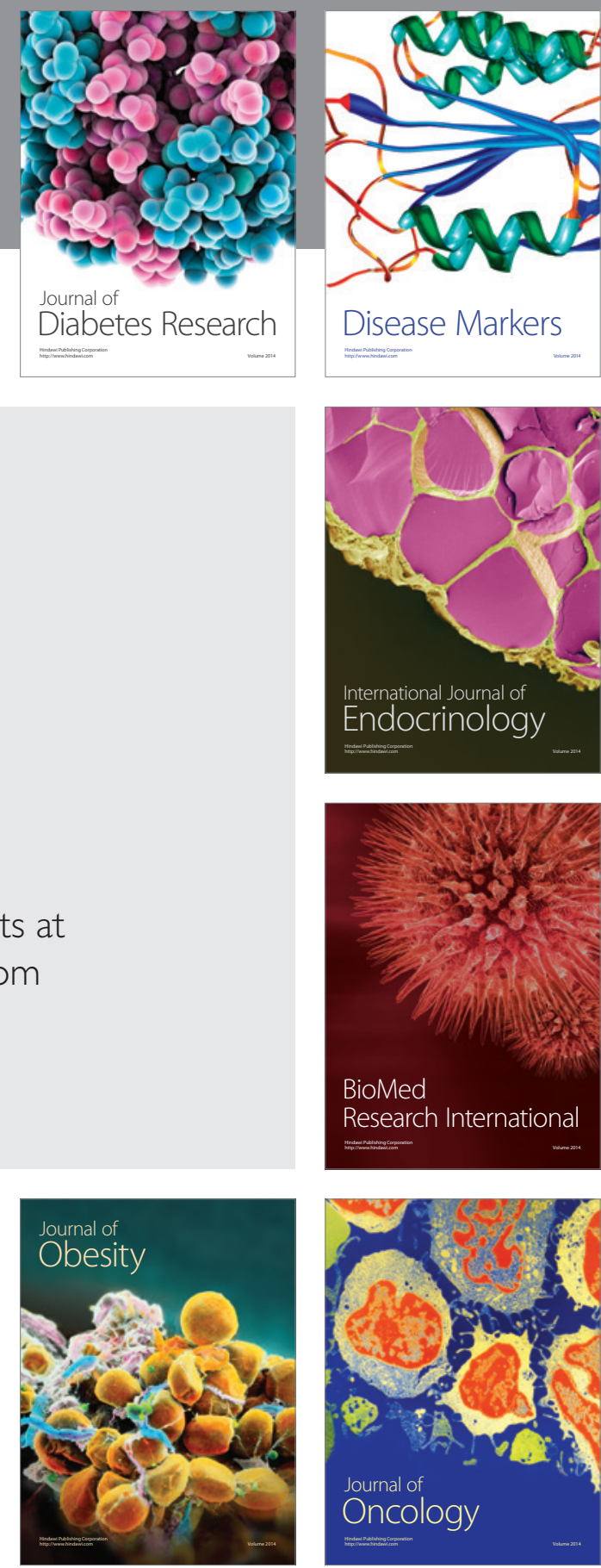

Disease Markers
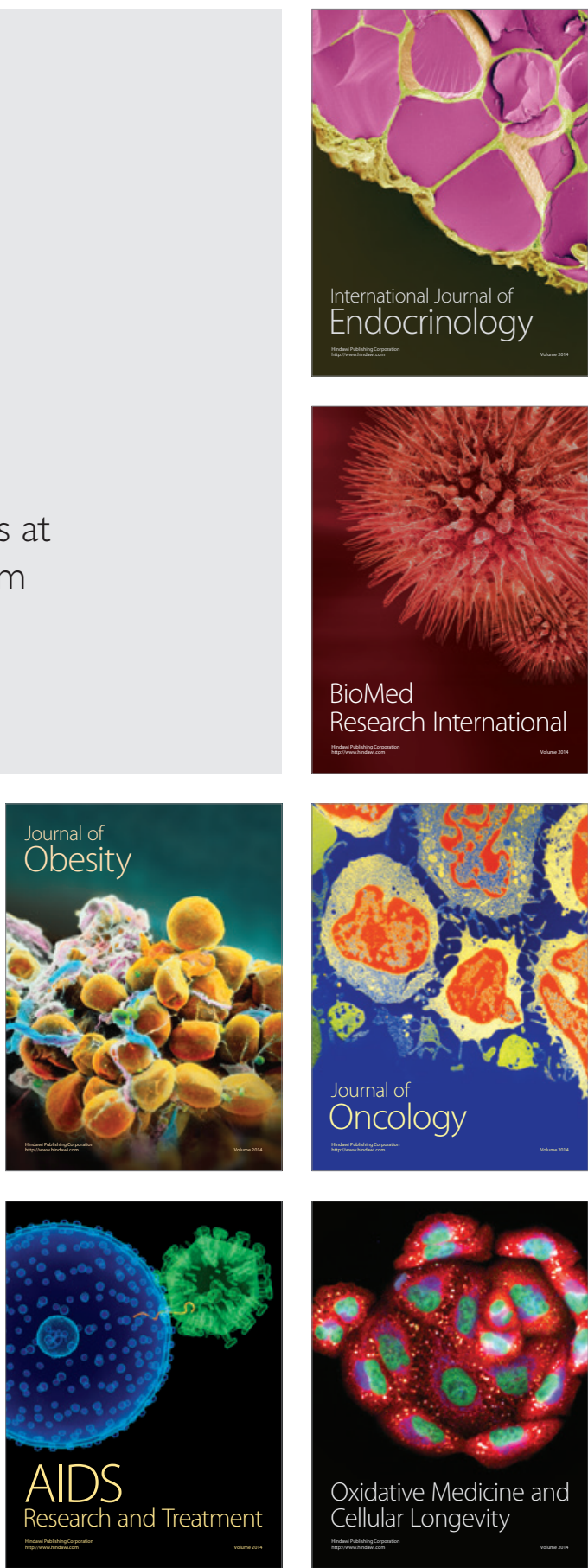